\title{
Use of Bedside Ultrasonography for Diagnosis of Nasal Fractures in Emergency Service
}

\author{
(1) Süleyman Ersoy ${ }^{1}$, (1) Turgut Tursem Tokmak², (1) Yeliz Dadalı3 , (1) Hacı Mehmet Çalıșkan ${ }^{1}$, (1) Mustafa Avcu ${ }^{4}$
}

1Department of Emergency Medicine, Ahi Evran University Faculty of Medicine, Kırşehir, Turkey
2Department of Radiology, Kayseri City and Education Hospital, Kayseri, Turkey
3Department of Radiology, Ahi Evran University Faculty of Medicine, Kırşehir, Turkey
4Department of Otorhinolaryngology, Ahi Evran University Faculty of Medicine, Kırşehir, Turkey

\begin{abstract}
Aim: In our study, the reliability of bedside ultrasonography (USG) in fracture diagnosis was evaluated in the cases who applied to emergency service due to nasal traumas.

Materials and Methods: Forty cases presented to the emergency department with nasal trauma between 01.01.2016 and 31.12.2017 were evaluated prospectively. The patients' age, gender, physical examination findings, trauma type, causes of trauma, X-ray and USG results were recorded in the study. The physical examination was performed by an emergency medicine specialist, and physical examination and $\mathrm{X}$-ray were accepted as the gold standard for diagnosis. In patients with suspected nasal fracture, physical examination and X-ray results were compared with USG in fracture diagnosis.

Results: The median age of the patients was 32.5 [interquartile range (IQR): 31], and $72.5 \%$ were male. There was no correlation between fracture presence with age or gender ( $p>0.05)$. The most common findings were swelling $(62.5 \%)$ and ecchymosis $(47.5 \%)$. $77.5 \%$ of patients had isolated trauma, and the most common cause of injury was falls (52.5\%). There was no correlation between the presence of fracture with the cause of trauma and the type of trauma $(\mathrm{p}>0.05)$. The sensitivity, specificity, positive predictive value and negative predictive value of USG were identified as $88.5 \%, 78.6 \%, 88.5 \%$ and $78.6 \%$, respectively

Conclusion: Bedside USG can be preferred as the first choice in diagnosing nasal fracture in patients applying to the emergency service due to nasal trauma.
\end{abstract}

Keywords: Nasal fractures, emergency service, bedside ultrasonography

\section{Introduction}

Compared to other maxillofacialstructures, the noseisanareathat is prone to trauma due to its excessive protrusion (1,2). In maxillofacial traumas, nasal fracture is the most common with a rate of $40 \%$ $58 \%(3,4)$. Detection and correction of nasal fracture accordingly is cosmetically and clinically important for the future $(1,5)$. Although physical examinations are considered gold standard for diagnosing nasal fractures, it is known that hematoma and edema of adjacent tissues make the diagnosis difficult (2). Imaging methods are often used in emergency service both for this cases and medico-legal reasons. Even though generally X-ray is used for imaging, gold standard is computerized tomography (CT). However, use of CT imaging for isolated nasal fractures in emergency service settings is not common. Ultrasonography (USG) is an easy, inexpensive, mobile and radiation-free diagnostic method that is frequently used in many areas of trauma. Recently, USG has been reported to be useful in detection of the presence of fracture in maxillofacial injuries (6). In last two decades, use of bedside USG in emergency service steadily increased and there have been studies on the use of bedside USG in the diagnosis of various fractures (metacarpal, metatarsal, radius, phalanx) in emergency department (7-9). In these studies, USG has been 
shown to have high sensitivity and specificity.

The aim of this study was to report the value of bedside USG for identification of nasal fractures in patients who apply to emergency service due to nasal trauma by correlating clinical findings and X-ray.

\section{Materials and Methods}

After the approval of the local ethics committee of Ankara Numune Training and Research Hospital (approval number: E-15691, date: 23.12.2015), our study was conducted prospectively in 40 patients in accordance with Helsinki Declaration. The study was conducted according to the criteria set by the World Medical Assocation Declaration of Helsinki 'Ethical Principles for Medical Research Involving Human Subjects'.

Our study was performed in patients who presented to the emergency department with nasal trauma and received X-ray and USG imaging due to suspicion of nasal fracture after physical examination between dates of 01.01.2016 and 31.12.2017. Age, gender, physical examination findings, trauma type and causes of trauma were evaluated in the study. In our study, we created a "composite gold standard diagnosis" using the findings of physical examination (crepitation and/or dislocation) and X-ray for detection of nasal fractures diagnosis, then we compared the results of physical examination and X-ray with USG.

Specificity, sensitivity, positive predictive value (PPD) and negative predictive values (NPD) of USG were calculated. Nasal USG was performed by a radiologist (with 15-years of experience) in patients who gave consent. Ultrasonography and direct radiography were evaluated by radiologists separately. A linear probe (ToshibaAplio500, Nasu, Japan) at 4-11 Mhz frequency was used for ultrasonography measurement. A water balloon was placed between the nose and the probe to get a better image (Figure 1).

The presence of cortical separation and staging in the nasal bone was considered significant for nasal fracture (Figure 2, Figure 3).

The reason why computed tomography was not preferred in this study even though it is gold standard was not to expose patients to radiation and for sole purpose of diagnosis of isolated nasal fractures it is not cost-effective.

Patients under 18 years of age, patients who refused to give consent, patients with open wound on the nasal dorsum and who had nasal fracture previously were excluded from the study.

\section{Statistical Analysis}

The data obtained were analyzed using Statistical Package for Windows version 22 (SPSS version 22). The distribution of the quantitative data was done by Kolmogrov-Smirnov test. In the representation of quantitative nonparametric data, median and inter-quantile range (IQR) were used, while the number of cases (n) and percentile (\%) were used for the representation of qualitative data. The Mann-Whitney $U$ test was used for the comparison of the quantitative data with the qualitative (categorical) data, the Pearson's square test and Fisher's exact test were used for the comparison of the qualitative data with each other. $p<0.05$ was considered significant.

\section{Results}

The median age of the patients was 32.5 (IQR: 31 ); and $72.5 \%$ were male in our study. There was no correlation between fracture presence with age or gender $(p>0.05)$. The most common findings were swelling (62.5\%) and ecchymosis (47.5\%). $77.5 \%$ of



Figure 1. Nasal ultrasonography was performed using water balloon in supine position with 4-11 MHz linear probe

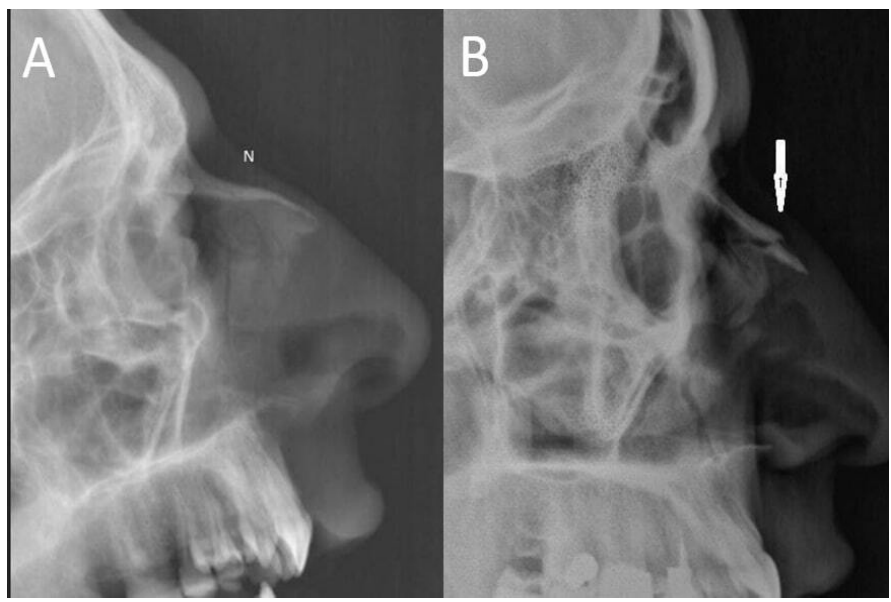

Figure 2. X-Ray Lateral Nasal view. Normal nasal bone formation is seen (A) and cortical separation and staging of the anterior nasal bone is observed (B) 
the patients were injured due to isolated trauma and $22.5 \%$ due to multi-trauma. The most common injuries were due to falls (52.5\%), followed by assaults (32.5\%) (Table 1).

The frequency of crepitations was significantly low in patients who was diagnosed with a fracture $(p<0.05)$. There was no correlation between the presence of fracture with the cause of trauma and the type of trauma $(p>0.05)$ (Table 1$)$.



Figure 3. Normal nasal bone sonographic examination is seen on the right image. On the left image, cortical separation and staging was detected secondary to nasal fracture (B: Baloon Water, N: Normal).
In patients whose fractures were identified with physical examination and X-ray, USG sensitivity, specifity, PPD and NPD were $88.5 \%, 78.6 \%, 88.5 \%$ and $78.6 \%$, respectively (Table 2 ).

\section{Discussion}

Ultrasonography is inexpensive, easy and non-invasive and allows high contrast imaging of even thin nasal bones at an appropriate frequency. In addition, high lateral resolution makes imaging of the smallest fractures and dislocations possible (10).

Studies have reported that patients presenting with nasal fracture are usually young males $(4,6,11,12)$. Mozeika et al. (13) stated that maxillofacial injuries are frequently seen in young men. In our study, the incidence of nasal trauma and fracture was more frequent in young male patients in accordance with the literature. In our study, no significant relationship was found between the presence of fracture with age or gender.

Aksakal et al. (11) reported that swelling (70.2\%) and hematoma (35.1\%) were the most common findings (11). In the study of Doğan et al. (14) it is stated that the most common finding was swelling (51.1\%) in children. In line with the literature, the most common symptom was swelling (62.5\%), followed by ecchymosis (47.5\%) and epistaxis (45\%) in our study. We think that the edema occurs easily due to the protrusion of the nasal region and the absence of a structure to suppress the edema around this region.

Table 1. Demographic and clinical characteristics of patients with nasal trauma

\begin{tabular}{|c|c|c|c|c|c|}
\hline & & \multirow{2}{*}{$\begin{array}{l}\text { Whole population } \\
\text { sample } \\
\text { Yes }(n=26)\end{array}$} & \multicolumn{2}{|l|}{ Fracture } & \multirow{2}{*}{ p-value } \\
\hline & & & No $(n=14)$ & & \\
\hline \multicolumn{2}{|l|}{ Age, Mean \pm SD } & $32.5(31)$ & $34.5(29)$ & $32(36)$ & $0.546^{*}$ \\
\hline \multirow{2}{*}{ Gender } & Male, n (\%) & $29(72.5)$ & $19(73.1)$ & $10(71.4)$ & \multirow{2}{*}{$>0.999 * * *$} \\
\hline & Female, n (\%) & $11(27.5)$ & 7 (26.9) & $4(28.6)$ & \\
\hline \multirow{5}{*}{ Symptom } & Swelling, n (\%) & $25(62.5)$ & $18(69.2)$ & $7(50)$ & $0.231 * *$ \\
\hline & Ecchymosis, n (\%) & $19(47.5)$ & $10(38.5)$ & $9(64.3)$ & $0.119 * *$ \\
\hline & Epistaxis, n (\%) & $18(45)$ & $11(42.3)$ & $7(50)$ & $0.641 * *$ \\
\hline & Crepitations, n (\%) & $11(27.5)$ & $11(42.3)$ & 0 & $0.004 * * *$ \\
\hline & Deviation, n (\%) & $6(15)$ & $6(23.1)$ & 0 & $0.074 * * *$ \\
\hline \multirow{2}{*}{ Type of trauma } & Isolated, n (\%) & $31(77.5)$ & $22(84.6)$ & $9(64.3)$ & \multirow{2}{*}{$0.234^{* * *}$} \\
\hline & Multi trauma, n (\%) & $9(22.5)$ & $4(15.4)$ & $5(35.7)$ & \\
\hline \multirow{5}{*}{ Cause of Trauma } & Falls, n (\%) & $21(52.5)$ & $13(50)$ & $8(57.1)$ & \multirow{5}{*}{$0.309 * * *$} \\
\hline & Assault, n (\%) & $13(32.5)$ & $10(38.5)$ & $3(21.4)$ & \\
\hline & Traffic accident, n (\%) & $4(10)$ & $3(11.5)$ & $1(7.1)$ & \\
\hline & Collision, n (\%) & $1(2.5)$ & 0 & $1(7.1)$ & \\
\hline & Animal Kick, n (\%) & $1(2.5)$ & 0 & $1(7.1)$ & \\
\hline
\end{tabular}


Table 2. Comparison of USG results to physical examination and X-ray

\begin{tabular}{|c|c|c|c|c|c|c|c|c|}
\hline \multirow{4}{*}{ USG fracture } & \multirow{4}{*}{$\begin{array}{l}\text { Yes }(n=26) \\
\text { No }(n=14)\end{array}$} & \multicolumn{6}{|c|}{ Physical examination $+X$-ray fracture } & \multirow{4}{*}{$\begin{array}{l}\mathrm{p} \text {-value } \\
<0.001\end{array}$} \\
\hline & & \multicolumn{3}{|c|}{ Yes $(n=26)$} & \multicolumn{3}{|c|}{ No $(n=14)$} & \\
\hline & & 21 & $88.5 \%$ & $88.5 \%$ & 5 & $35.7 \%$ & $35.7 \%$ & \\
\hline & & 5 & $19.2 \%$ & $19.2 \%$ & 9 & $78.6 \%$ & $78.6 \%$ & \\
\hline & \multicolumn{8}{|l|}{ Sensitivity } \\
\hline & \multicolumn{8}{|l|}{ Specificity } \\
\hline & \multicolumn{8}{|c|}{ Negative predictive value } \\
\hline
\end{tabular}

Aksakal et al. (11) reported that the most common cause of nasal injury was assault (40.5\%) and falling (36.5\%). Pham et al. (4) reported that nasal fractures usually develop as a result of blunt trauma (90.5\%) and the most common causes were traffic accidents (27.5\%) and falls (25.4\%). It was reported that the most common cause of isolated fractures was falls in that study (4). Park et al. (1) reported that the most common cause of nasal fractures was fighting (40.6\%). In our study, it was found that nasal injuries generally developed as a result of isolated injuries (77.5\%), and the most common causes of injury were falls (52.5\%) and assault (32.5). In our study, no significant relationship was found between the presence of fracture with the cause of trauma and the type of trauma.

Although tomography has been reported to be the best imaging tool for nasal fractures $(5,6)$; many studies reported that USG and CT showed similar results in the detection of nasal fractures $(1,2,5)$. Even though Lee et al. (5) reported that CT is much better than X-ray for detecting fractures; they also reported that USG has similar sensitivity to CT and better specificity for detecting nasal bone midline fractures, better PPV and NPV than CT. In the same study, it was reported that CT has more sensitivity than USG in detecting lateral nasal bone fractures (5). The fact that USG is better than $\mathrm{CT}$ in midline fractures has been attributed to thicksection CT images bypassing thin fracture lines (15).

In the study of Mohammadi et al. (16) sensitivity of nasal bone fracture detection rates for USG, CT and X-ray were 97\%, 100\% and $86 \%$ while specificity rates of USG, CT and X-ray were $87 \%$, $72 \%$ and $73 \%$, respectively. AL-Bahrany et al. (17) reported that the sensitivity of USG in nasal fractures was 76.6\%. Lee et al. (5) found that sensitivity, specificity, PPV and NPV of USG according to localization of fracture were $70-80 \%, 75-90 \%, 50-72.7 \%$ and 86.4-93.3\%, respectively. Caglar et al. (18) found that USG had a sensitivity of $84.8 \%$, specificity of $93 \%$, PPV of $90.7 \%$, and NPV of 88.3\% compared with radiography. Gürkov et al. (19) reported that compared to USG, the specificity of X-ray was higher for identification of lateral nasal bone fractures (75\% and 94\%).
However, the sensitivity of USG for identification of fractures of lateral nasal bone were significantly higher comparing to X-ray (98\% and 28\%). In our study; sensitivity, specificity, positive predictive value and negative predictive value of USG were $88.5 \%, 78.6 \%, 88.5 \%$ and $78.6 \%$, respectively. According to our results, USG had high sensitivity for identifying fractures of nasal bone, in line with the literature.

We think that bedside USG can be used as the first choice especially in cases where radiation is avoided such as pregnancy in the emergency department for the detection of nasal fracture with suspicious physical examination because it is repeatable, documentable, cost-effective and due to its non-radiation, no required preparation, rapid and bedside application.

\section{Study Limitations}

The most important limitation of our study was the small sample of cases. Another limitation which should mentioned was that we did not compare ultrasonography with CT which is the golden standard. This limitation stem from avoiding unnecessary radiation exposure and no requirement of additional imaging in existing traumas. Also, these results might not be confirmed in another center due to USG being operator-dependent.

\section{Conclusion}

We think that bedside USG can be preferred as the first choice in the diagnosis of nasal fracture in patients presenting to the emergency service with a nasal trauma, because of its high sensitivity in the diagnosis of nasal fracture. Further studies are needed on this subject.

There is no conflict of interest between the authors.

\section{Ethics}

Ethics Committee Approval: This study was approved by the Ethics Committee of Ankara Numune Training and Research Hospital (approval number: E-15-691, date: 23.12.2015).

Informed Consent: It was obtained. 
Peer-review: Externally peer-reviewed.

\section{Authorship Contributions}

Surgical and/or Medical Practices: S.E., Concept: S.E., T.T.T., M.A., Design: S.E., T.T.T, Y.D., Data Collection and/or Processing: S.E., Y.D., H.M.C.., Analysis and/or Interpretation: S.E., Y.D., M.A., Literature Search: S.E., T.T.T., Writing: S.E.

Conflict of Interest: No conflict of interest was declared by the authors.

Financial Disclosure: The authors declared that this study received no financial support.

\section{References}

1. Park $\mathrm{CH}$, Joung $\mathrm{HH}$, Lee JH, Hong SM. Usefulness of ultrasonography in the treatment of nasal bone fractures. J Trauma. 2009;67:1323-6.

2. Javadrashid R, Khatoonabad M, Shams N, Esmaeili F, Jabbari Khamnei H. Comparison of ultrasonography with computed tomography in the diagnosis of nasal bone fractures. Dentomaxillofac Radiol. 2011;40:486-91.

3. Greathouse ST, Adkinson JM, Garza R 3rd, Gilstrap J, Miller NF, Eid SM, Murphy RX Jr. Impact of Injury Mechanisms on Patterns and Management of Facial Fractures. J Craniofac Surg. 2015;26:1529-33.

4. Pham TT, Lester E, Grigorian A, Roditi RE, Nahmias JT. National Analysis of Risk Factors for Nasal Fractures and Associated Injuries in Trauma. Craniomaxillofac Trauma Reconstr. 2019;12:221-7.

5. Lee IS, Lee JH, Woo CK, Kim HJ, Sol YL, Song JW, et al. Ultrasonography in the diagnosis of nasal bone fractures: a comparison with conventional radiography and computed tomography. Eur Arch Otorhinolaryngol. 2016;273:413-8

6. Yabe T, Tsuda T, Hirose S, Ozawa T, Kawai K. Comparison of ultrasonographyassisted closed reduction with conventional closed reduction for the treatment of acute nasal fractures. J Plast Reconstr Aesthet Surg. 2014;67:1387-92.
7. Su DC, Chang KV. Mid-foot cellulitis? Ultrasound imaging of stress fracture at the third metatarsal bone. Kaohsiung J Med Sci. 2016;32:162-3.

8. Kozaci N, Ay MO, Akcimen M, Sasmaz I, Turhan G, Boz A. The effectiveness of bedside point-of-care ultrasonography in the diagnosis and management of metacarpal fractures. Am J Emerg Med. 2015;33:1468-72.

9. Sabzghabaei A, Shojaee M, Arhami Dolatabadi A, Manouchehrifar M, Asadi M. Ultrasound-Guided Reduction of Distal Radius Fractures. Emerg (Tehran). 2016;4:132-5.

10. Gruss JS, Van Wyck L, Phillips JH, Antonyshyn O. The importance of the zygomatic arch in complex midfacial fracture repair and correction of posttraumatic orbitozygomatic deformities. Plast Reconstr Surg. 1990;85:87890

11. Aksakal C, Ertaş İ. Analysis of patients with isolated nasal fracture applied to emergency department. J Contemp Med. 2018;8:206-10.

12. Lee MH, Cha JG, Hong HS, Lee JS, Park SJ, Paik SH, Lee HK. Comparison of high-resolution ultrasonography and computed tomography in the diagnosis of nasal fractures. J Ultrasound Med. 2009;28:717-23.

13. Mozeika AM, Sachdev D, Asri R, Farber N, Paskhover B. Sociological and Medical Factors Influence Outcomes in Facial Trauma Malpractice. J Oral Maxillofac Surg. 2019;77:1042.e1-1042.e10.

14. Dogan S, Kalafat UM, Yüksel B, Karaboğa T, Basturk M, Ocak T. Use of radiography and ultrasonography for nasal fracture identification in children under 18 years of age presenting to the ED. Am J Emerg Med. 2017;35:465-8.

15. Daly BD, Russell JL, Davidson MJ, Lamb JT. Thin section computed tomography in the evaluation of naso-ethmoidal trauma. Clin Radiol. 1990;41:272-5.

16. Mohammadi A, Ghasemi-Rad M. Nasal bone fracture--ultrasonography or computed tomography? Med Ultrason. 2011;13:292-5.

17. AL-Bahrany ZM, AL-Nakib LH. Comparison Between High-Resolution Ultrasonography and Conventional Radiography in the Diagnosis of Nasal Bone Fractures. Tikrit Journal for Dental Sciences. 2011;1:6-13

18. Caglar B, Serin S, Akay S, Yilmaz G, Torun A, Adıbelli ZH, et al. The accuracy of bedside USG in the diagnosis of nasal fractures. Am J Emerg Med. 2017;35:1653-6.

19. Gürkov R, Clevert D, Krause E. Sonography versus plain $x$ rays in diagnosis of nasal fractures. Am J Rhinol. 2008;22:613-6. 